Review

\title{
Heavy Metals and Metalloids as Autophagy Inducing Agents: Focus on Cadmium and Arsenic
}

\section{Roberto Chiarelli and Maria Carmela Roccheri *}

Dipartimento di Scienze e Tecnologie Molecolari e Biomolecolari STEMBIO, Università di Palermo, Viale delle Scienze Edificio 16, Palermo 90128, Italy; E-Mail: roberto.chiarelli@unipa.it

* Author to whom correspondence should be addressed; E-Mail: maria.roccheri@unipa.it; Tel.: +39-09123897414.

Received: 19 July 2012; in revised form: 10 August 2012 / Accepted: 14 August 2012 /

Published: 27 August 2012

\begin{abstract}
In recent years, research on the autophagic process has greatly increased, invading the fields of biology and medicine. Several markers of the autophagic process have been discovered and various strategies have been reported studying this molecular process in different biological systems in both physiological and stress conditions. Furthermore, mechanisms of metalloid- or heavy metal-induced toxicity continue to be of interest given the ubiquitous nature and distribution of these contaminants in the environment where they often play the role of pollutants of numerous organisms. The aim of this review is a critical analysis and correlation of knowledge of autophagic mechanisms studied under stress for the most common arsenic (As) and cadmium (Cd) compounds. In this review we report data obtained in different experimental models for each compound, highlighting similarities and/or differences in the activation of autophagic processes. A more detailed discussion will concern the activation of autophagy in Cd-exposed sea urchin embryo since it is a suitable model system that is very sensitive to environmental stress, and $\mathrm{Cd}$ is one of the most studied heavy metal inductors of stress and modulator of different factors such as: protein kinase and phosphatase, caspases, mitochondria, heat shock proteins, metallothioneins, transcription factors, reactive oxygen species, apoptosis and autophagy.
\end{abstract}

Keywords: autophagy; apoptosis; arsenic; cadmium; stress; sea urchin embryos 


\section{Introduction}

\subsection{Autophagy}

Macro-autophagy, here after referred to as autophagy, is a major intracellular pathway for the degradation and recycling of cytosolic components, in both basal and stress conditions, in eukaryotic cells. Autophagy is a process of bulk degradation of toxic protein aggregates and damaged organelles, in which portions of the cytoplasm are sequestered into double-membrane vesicles known as autophagosomes, and then fuse with lysosomes to form single-membrane autolysosomes; ultimately, the contents of autolysosomes are degraded by lysosomal hydrolases and recycled for energy utilization. In this context, autophagy is involved in cell survival [1]. The execution and regulation of the autophagic program occurs by the expression of several autophagy-related (Atg) genes, having a high degree of conservation among species, from yeast to human. Depending on the environmental stress and cell type, this pathway acts as either a survival or death safeguard mechanism. However, massive and persistent autophagy can kill severely damaged cells by a caspase-independent form of cell death, termed type II cell death [2,3].

Similarly to apoptotic programmed cell death, autophagy is an essential part of embryo development, growth regulation and maintenance of homeostasis in multicellular organisms. Autophagy is critical to the process of embryo development because some animal models have shown that the lack of autophagy leads to arrest, delays or defects in development [4].

Autophagy responds to the cellular environment, and therefore any alteration in the environment may lead to the dysregulation of this process, potentially resulting in cell death.

The autophagic process occurs constitutively at basal levels and appears to be activated as an adaptive response to a variety of intracellular and extracellular stimuli, including nutrient deprivation (starvation), hormonal treatments, bacterial or viral infections, accumulation of misfolded proteins and damaged organelles, toxic stimuli, radiation and many agents of stress. In general, it seems that autophagy is necessary for cell survival under stress through removal of damaged proteins and organelles. There is a potential link between autophagy and a number of human diseases, such as cancer, cardiomyopathy, and neurodegenerative disorders, including Alzheimer's, Parkinson's, and Huntington's.

Furthermore, autophagy may also be a strategy for self-destruction through the induction of programmed cell death (PCD), which is different from apoptosis. PCD is an essential and highly orchestrated process, which plays an important role in the development, cellular homeostasis, and prevention of cancer cell growth. The two main PCD types are referred to as apoptosis (PCD I) and autophagy (PCD II) [5].

There is emerging evidence that autophagy plays a critical role in the generation of antineoplastic responses [6,7]. Depending on the cellular context, autophagy may act as a protective mechanism for malignant cells or exhibit opposing effects and promote antineoplastic responses [8-10]. In fact, tumor growth in response to either blocked or induced autophagy has been described [11]. Some evidence suggests that autophagy may have an anticancer role: The autophagy gene beclin-1 acts as a tumor suppressor in mice and is monoallelically deleted in $40-75 \%$ of human breast, ovarian and prostate tumors $[12,13]$. Furthermore, the established tumor suppressor gene p53 induces 
autophagy $[14,15]$ whereas the oncogenic proteins Bcl-2 and Bcl-XL interact with Beclin-1 to inhibit autophagy [16]. However, in certain circumstances, Bcl-2/Bcl-xL may have opposite effects on autophagy, depending on whether they are associated with mitochondria or the ER [17]. In addition, AKT activation (which is increased in many cancers) leads to increased mTOR activation and blockage of autophagy. Indeed, rapamycin and its derivatives inhibit mTOR activation, induce autophagic cell death and are under clinical investigation as anti-cancer compounds [18].

On the other hand, there is evidence that defects in autophagic responses are associated with tumorigenesis [19], whereas various inductors of autophagy exhibit tumor suppressor activities [20,21].

Autophagy is considered one of the most important molecular responses against different environmental stress agents and can be considered as a biomarker of toxicants. More knowledge regarding this process could provide valuable toxicological data for hazard and risk assessment.

In this review we considered the effect of some non-essential heavy metals in different model systems correlated to autophagy.

\subsection{Heavy Metals and Metalloids}

The environment is composed of the atmosphere, earth and water. According to the World Health Organization, more than 100,000 chemicals are released into the global environment every year as a consequence of their production, use and disposal. The fate of a chemical substance depends on its chemical application and physical-chemical properties, in combination with the characteristics of the environment where it is released. Chemical substances or contaminants discharged into the environment may be "natural", a substance that can occur without human introduction, or vice versa "manmade". The chemicals, both from natural and anthropogenic sources, are of considerable interest based on their ability to induce the activation of defense systems or interrupt the developmental program. Among these substances we consider the heavy metals. The term heavy metal refers to any metallic chemical element that has a relatively high density and is toxic or poisonous at low concentrations.

Approximately 30 metals and metalloids are potentially toxic to humans; examples include mercury $(\mathrm{Hg})$, cadmium $(\mathrm{Cd})$, chromium $(\mathrm{Cr})$, lead $(\mathrm{Pb})$, and arsenic (As). As trace elements, some heavy metals (e.g., copper, selenium, zinc) are essential to maintain the metabolism of organisms; however, at higher concentrations, they can lead to poisoning.

Heavy metals, as they are not biodegradable and persistent in the environment for long periods, cause serious eco-toxicological problems. In addition, some toxic metals may mimic essential metals and thereby gain access to important molecular targets. To a small extent they enter into organisms via food, drinking water and air and are bio-persistent pollutants that accumulate at the top of the food chain [22]. Heavy metals can enter a water supply by industrial and consumer waste, or even from acidic rain breaking down soils and releasing heavy metals into streams, lakes, rivers, and groundwater.

Heavy metals and metalloids are dangerous because they tend to bioaccumulate. Bioaccumulation means an increase in the concentration of a chemical in a biological organism over time compared to its concentration in the environment. Compounds accumulate in living things any time they are taken up and stored faster than they are broken down (metabolized) or excreted. 
Compounds of heavy metals and metalloids are known to be stress agents and in some cases, as well as inducing apoptosis, are able to trigger autophagy.

\section{The Effects of Heavy Metals and Metalloids on Cells}

\subsection{Arsenic}

Arsenic (As) is a metalloid that is rarely found as a free element in the natural environment. It is abundant in the Earth's crust and is variously distributed in soils, detectable in many waters, and in almost all tissues of animals and plants. A substantial amount of As, in various chemical forms and in various oxidation states, may be present in the environment both based on the effect of erosion processes and as a consequence of production by human activities. As has two oxidative states: a trivalent form and a pentavalent form, moreover, in is found in the form of arsenous acid $\left(\mathrm{H}_{3} \mathrm{AsO}_{3}\right)$ and its salts, and arsenic acid $\left(\mathrm{H}_{3} \mathrm{AsO}_{5}\right)$ and its salts.

As compounds are well-known toxic and carcinogenic agents, which, depending on oxidation state and chemical species, cell type, exposure concentrations, and time, can induce apoptosis. Because As is an ubiquitous contaminant, organisms are constantly exposed to this metal. The toxic effects of As that are of most concern to humans are those that occur from chronic, low-level exposure, and are associated with a range of human diseases, including various internal cancers. The genotoxic and co-genotoxic effects of inorganic arsenicals are well documented in mammalian systems, both in vitro [23] and in vivo [24].

Arsenic trioxide $\left(\mathrm{As}_{2} \mathrm{O}_{3}\right)$ has a long history of use as a pharmaceutical agent for its antitumor properties. However, $\mathrm{As}_{2} \mathrm{O}_{3}$ has had a mainly unfavorable reputation due to its poisonous or environmental toxicity. Recently, $\mathrm{As}_{2} \mathrm{O}_{3}$ has shown considerable efficacy in treating patients with acute promyelocytic leukemia (APL). $\mathrm{As}_{2} \mathrm{O}_{3}$ activates numerous intracellular signal transduction pathways (including ROS, mitochondrial disruption, caspase activation, p53, and the MAPK signaling pathway), resulting in induction of apoptosis, promotion of differentiation, or inhibition of angiogenesis [25,26].

Although much is known about the mechanisms by which the arsenic compounds induce apoptosis, very little is known about the potential involvement of autophagy as a regulator of As-dependent neoplastic cell death. Recent studies have shown that it could cause autophagic cell death in malignant cells, including leukemia and malignant glioma cells.

$\mathrm{As}_{2} \mathrm{O}_{3}$ has important anti-leukemic effects in vitro and in vivo and is known to mediate its effects via its ability to induce apoptosis. Current research has revealed that autophagy can be an alternative or accompanying process to apoptosis in As-exposed cells. Goussetis et al., [27] examined the capability of $\mathrm{As}_{2} \mathrm{O}_{3}$ to induce autophagic cell death in leukemic cell lines: Their data demonstrate that As is a potent inducer of autophagy, but not apoptosis [28], and such an induction is mediated by engagement of the MEK/ERK pathway. Interestingly, it has been demonstrated that a treatment of acute promyelocytic leukemia with $\mathrm{As}_{2} \mathrm{O}_{3}$ is one of the most successful examples of targeted cancer therapy that is being used in the clinic at present. This treatment causes proteolytic degradation of a highly oncogenic protein, the PML/RARA fusion protein that sustains malignant transformation supporting concomitant disease remission. Autophagy appears to regulate the basal turnover of PML/RARA: 
Autophagy-mediated suppression of this oncoprotein may represent a tumor-suppressor mechanism that prevents or delays the onset of this type of cancer [29]. In the human T-lymphocytic leukemia cell line Molt-4, $\mathrm{As}_{2} \mathrm{O}_{3}$ induces autophagy through the up-regulation of Beclin-1 (a $60-\mathrm{kDa}$ coiled-coil protein essential for autophagosome formation), as an additional mechanism to apoptosis [30].

In HL-60, an acute promyelocytic leukemia cell line, several groups have established the induction of apoptosis by As through mechanisms that may be initiated by reactive oxygen species (ROS) generation as well as direct As targeting of the mitochondrial permeability transition pore [31,32]. Morphological characteristics of apoptosis (membrane blebbing, chromatin condensation) in HL-60 cells exposed to several As species, with particular potency in the trivalent arsenicals were documented [33,34]. On the other hand, a study by Yang et al., [35] have provided evidence that arsenic trioxide-exposed HL-60 cells undergo cytotoxicity that is characterized by apoptosis, but also concurrently by autophagy. The data suggest that autophagy has differential effects on the $\mathrm{As}_{2} \mathrm{O}_{3}$-induced death of HL60 cells: It may be a protective mechanism against apoptosis in the earlier period of $\mathrm{As}_{2} \mathrm{O}_{3}$ treatment, while it promotes apoptosis and/or leads to autophagic death in the later period of $\mathrm{As}_{2} \mathrm{O}_{3}$ treatment.

Autophagy that regulates cell survival may act through interference with the mitochondria-mediated apoptotic pathway. It is believed that the antitumor efficacy of As involves the inhibition of proliferation and the triggering of apoptosis in tumor cells, but the relationship between autophagy and apoptosis and its antitumor effects still remain obscure. The process of autophagy could lead to "mitochondrial quality control": Prevention of oxidative damage and mutagenesis through the removal of damaged mitochondria, which are a major source of toxic ROS [36]. Some investigators have shown that ROS regulate autophagy through several different mechanisms, including up-regulation of Beclin-1, oxidation of Atg4 and by causing mitochondrial dysfunction [37]. Since both ROS and autophagy are involved in cancer initiation and progression, it is thus essential to consider the regulation of ROS-induced autophagy in the development of cancer therapeutics [38]. Hence it is possible that autophagy may be an alternative process for the generation of the antitumor effects in other malignant cell types.

It has been shown that in human malignant glioma cells, the most common and lethal tumor in the central nervous system, As induces autophagic cell death but not apoptosis. Specifically, cell death included the involvement of autophagy-specific marker LC3 (microtubule-associated protein light chain 3) and was accompanied by damage of mitochondrial membrane integrity, but not by caspase activation. In that case a novel mechanism has been implicated, suggesting the possibility that $\mathrm{As}_{2} \mathrm{O}_{3}$ may induce a hypoxic state in tumor cells and subsequently, through up-regulation of a mitochondrial cell death protein (BNIP3), lead to autophagic cell death [28]. But in recent years it has become evident that the up-regulation of autophagy is often wrongfully described as an alternative cell death program [39]. Therefore autophagy may, as we reported, also serve as a pro-survival mechanism and its up-regulation therefore reflects the cell's attempt to counteract death signaling.

Recently, it has also been shown that arsenic trioxide induces a Beclin-1 independent autophagic pathway in ovarian carcinoma cells [40]. In fact, these authors observed that $\mathrm{As}_{2} \mathrm{O}_{3}$ alters the expression of TGF $\beta$ signaling mediators via the generation of reactive oxygen species (ROS). Their results suggest that the increase in SnoN (a TGF $\beta$ signaling mediator) expression leads to changes in 
LC3-II levels, implicating a role for $\mathrm{SnoN}$ in $\mathrm{As}_{2} \mathrm{O}_{3}$-induced autophagy, which could potentially bypass the apoptotic pathway. SnoN can be considered a novel therapeutic target for ovarian cancers.

Human lymphoblastoid cell lines (LCL) have been used as a model system in arsenic toxicology for many years, but the exact mechanism of As-induced cytotoxicity in LCL is still unknown. Bolt et al., [41] investigated the cytotoxicity of sodium arsenite in LCL 18564 using a set of complementary markers for cell death pathways. Markers indicative of apoptosis (phosphatidylserine externalization, PARP cleavage, and sensitivity to caspase inhibition) were uniformly negative in arsenite-exposed cells. Interestingly, electron microscopy, acidic vesicle fluorescence, and expression of LC3 protein in LCL identified autophagy as an arsenite-induced process that was associated with cytotoxicity. Autophagy appeared to be the predominant process in LCL cytotoxicity induced by arsenite. It was unclear, however, whether LCL autophagy was an effector mechanism of arsenite cytotoxicity or alternatively a cellular compensatory mechanism. For this reason the authors, in a subsequent study, characterized As-induced effects in LCL cultures derived from seven human donors exposed in vitro to levels of sodium arsenite $(0.75 \mu \mathrm{M})$ commonly encountered in the environment, and hence minimally cytotoxic. As-exposure resulted in inhibition of cellular growth and induction of autophagy, measured by the expansion of acidic vesicles, over the eight-day exposure duration. Gene expression analysis revealed that As-exposure increased global lysosomal gene expression, which was associated with increased functional activity of the lysosome protease, cathepsin D [42]. This is the first report of As-exposure modulating the regulation of genes encoding lysosomal constituents. The lysosome, historically considered a dead end for damaged cellular contents, is emerging as a critical player that actively maintains cellular homeostasis.

Tetraarsenic hexoxide $\left(\mathrm{As}_{4} \mathrm{O}_{6}\right)$ has been used as anticancer in U937 human leukemic cells: The growth of U937 cells was inhibited by this treatment in a dose- and a time-dependent manner. This study suggests that $\mathrm{As}_{4} \mathrm{O}_{6}$ should induce Beclin-1-induced autophagic cell death as well as caspase-dependent apoptosis and that it might be a promising agent for the treatment of leukemia [43]. A comparison study of the anticancer effects between $\mathrm{As}_{2} \mathrm{O}_{3}$ and $\mathrm{As}_{4} \mathrm{O}_{6}$ demonstrated that $\mathrm{As}_{4} \mathrm{O}_{6}$ was more effective in suppressing human cancer cells in vitro and in vivo, and that the $\mathrm{As}_{4} \mathrm{O}_{6}$-induced cell death pathway was different from that of $\mathrm{As}_{2} \mathrm{O}_{3}$ [44].

A study by Huang et al., [45] provides the first evidence that the human uroepithelial cells in vitro respond directly, within $48 \mathrm{~h}$ of exposition to sodium arsenite, by promoting extensive vacuolation. They suggest that As induces cell death not only via apoptosis but also via autophagy, increasing LC3B and Beclin-1 protein expression, maybe via the ERK signaling pathway.

\subsection{Arsenic in Combination with Other Heavy Metals or Radiation}

Arsenic trioxide has also been used in combination with other treatments, such as ionizing radiation or heavy metals. Chiu et al., [46,47] investigating the anticancer effects of ionizing radiation combined with arsenic trioxide in human malignant glioma cells and in human fibrosarcoma cells, in vitro and in vivo, found that this combined treatment increased cell death, inducing autophagy and apoptosis, compared to individual treatments. Furthermore, these researchers discovered that the combined treatment was affected by the inhibition of PI3K/AKT and the activation of ERK1/2, signaling pathways involved in regulating autophagy. Conversely, Larson et al., [48] found that large alterations 
in the expression of Beclin-1 and associated proteins (essential effectors of autophagy) did not occur when human urothelial cells were malignantly transformed with, or exposed to, either $\mathrm{Cd}_{2}+$ or $\mathrm{As}_{3}+$.

Representative data from experiments performed in different model systems are reported in Table 1.

Table 1. Arsenic concentration and induced cellular response with respect to autophagy.

\begin{tabular}{|l|c|c|c|}
\hline $\begin{array}{l}\text { As compounds } \\
\text { (concentrations) }\end{array}$ & Autophagic effects & $\begin{array}{c}\text { Experimental } \\
\text { model }\end{array}$ & References \\
\hline $\mathrm{As}_{2} \mathrm{O}_{3}(2 \mu \mathrm{M})$ & $\begin{array}{c}\text { autophagic cell death, by activation of the } \\
\text { MEK/ERK pathway; antileukemic effects }\end{array}$ & $\begin{array}{c}\text { human leukemia } \\
\text { cells }\end{array}$ & {$[27]$} \\
\hline $\mathrm{As}_{2} \mathrm{O}_{3}(0,625-20 \mu \mathrm{M})$ & $\begin{array}{c}\text { autophagic cell survival, in the earlier period of } \\
\text { treatment; apoptosis and/or autophagic cell death, } \\
\text { in the later period of treatment }\end{array}$ & $\begin{array}{c}\text { HL60 leukemia } \\
\text { cells }\end{array}$ & {$[35]$} \\
\hline $\mathrm{As}_{2} \mathrm{O}_{3}(1 \mu \mathrm{M})$ & $\begin{array}{c}\text { autophagy as clearance mechanism of the fusion } \\
\text { protein PML/RARA }\end{array}$ & $\begin{array}{c}\text { human leukemia } \\
\text { cells }\end{array}$ & {$[29]$} \\
\hline $\mathrm{As}_{2} \mathrm{O}_{3}(4 \mu \mathrm{M})$ & $\begin{array}{c}\text { autophagic cell death, by up-regulation of Beclin- } \\
1, \text { as well as apoptosis }\end{array}$ & $\begin{array}{c}\text { human leukemia } \\
\text { cells }\end{array}$ & {$[30]$} \\
\hline $\mathrm{As}_{4} \mathrm{O}_{6}(0.5-3 \mu \mathrm{M})$ & $\begin{array}{c}\text { autophagic cell death, by up-regulation of Beclin- } \\
1, \text { as well as apoptosis, by caspase activation }\end{array}$ & $\begin{array}{c}\text { U937 human } \\
\text { leukemia cells }\end{array}$ & {$[43]$} \\
\hline $\mathrm{As}_{2} \mathrm{O}_{3}(1-4 \mu \mathrm{M})$ & $\begin{array}{c}\text { autophagic cell death, by up-regulation of BNIP3 } \\
\text { and ERK 1/2, down-regulation of PI3K/AKT; } \\
\text { antitumor effects }\end{array}$ & $\begin{array}{c}\text { human malignant } \\
\text { glioma cells }\end{array}$ & {$[28,46]$} \\
\hline $\mathrm{NaAsO}_{2}(1-10 \mu \mathrm{M})$ & $\begin{array}{c}\text { autophagic cell death, including increased levels } \\
\text { of LC3B and Beclin-1, as well as apoptosis }\end{array}$ & $\begin{array}{c}\text { human } \\
\text { uroepithelial cells }\end{array}$ & {$[45]$} \\
\hline $\mathrm{NaAsO}_{2}(6 \mu \mathrm{M})$ & $\begin{array}{c}\text { autophagic cell death, including increased levels } \\
\text { of LC3-II and autophagosomes/autolysosomes, } \\
\text { not associated with apoptosis }\end{array}$ & $\begin{array}{c}\text { human } \\
\text { lymphoblastoid } \\
\text { cells }\end{array}$ & {$[41,42]$} \\
\hline
\end{tabular}

\subsection{Cadmium}

Cadmium (Cd), commonly detected in aquatic and terrestrial environments, is a heavy metal released both from natural sources (e.g., volcanism, erosion) and anthropogenic activities (e.g., pigments, nickel-cadmium batteries, smelting and refining of metals and many other sources). The presence in the environment of this metal has increased because of its large utilization in some industrial and agricultural activities. $\mathrm{Cd}$ is a potent cell poison that causes different types of damage including cell death, and is a highly toxic environmental pollutant.

The toxicity associated to $\mathrm{Cd}$ for living organisms, even at low concentrations, is amplified as a consequence of the long biological half-life of the metal. The metal is highly dangerous not only because it easily penetrates the cells via transport mechanisms normally used for other purposes, but also because it is eliminated very slowly, as it is not prone to bacterial degradation or detoxification.

Since $\mathrm{Cd}$ is a non-essential metal, which is not physiologically present in organisms, it is irreversibly accumulated in cells, interacting with cellular components and molecular targets. Cd toxicity has been associated with: blockage of oxidative phosphorylation, glutathione depletion and inhibition of antioxidant enzymatic activity, production of ROS, DNA damage and inhibition of 
relative repair mechanisms, and also to general reduction of protein synthesis coupled to an increase in stress proteins (HSPs) [49].

$\mathrm{Cd}$ has toxic effects on the lungs, kidneys, liver, and immune system. Furthermore the occurrence of apoptotic events after $\mathrm{Cd}$ exposure has been demonstrated in numerous organisms and cell lines. Human exposure occurs by inhalation (cigarette smoke) and by ingestion of Cd-contaminated food or water.

$\mathrm{Cd}$ also acts as a cancer promoter that causes transformation in cultured cell lines [50] and produces malignant tumors in testes, prostate, lungs, pancreas and liver of experimental animals. In addition to effects on gene expression and DNA repair, $\mathrm{Cd}$ carcinogenesis probably involves inhibition of apoptosis [51]. In any case, the outcome for a cell exposed to $\mathrm{Cd}$ is dependent not only upon the duration and level of exposure, but also on other factors intrinsic to the cell itself, and its current metabolic state.

Some of the pathways leading to cell death and survival in mesangial cells are summarized in a review by Templeton et al., [52]. The authors report that the effects of $\mathrm{Cd}$ depend on the concentration levels in exposed cells: Low concentrations $\left(0.5 \mu \mathrm{M} \mathrm{CdCl}_{2}\right)$ lead to proliferation or delayed apoptosis, intermediate concentrations $\left(10 \mu \mathrm{M} \mathrm{CdCl}_{2}\right)$ can induce autophagy and/or cause various types of apoptotic death, and only very high concentrations $\left(>50 \mu \mathrm{M} \mathrm{CdCl}_{2}\right)$ provoke necrosis.

On the other hand, a recent study by Yang et al., [53] shows that Cd treatment induces death in mesangial cells, leading to nephrotoxicity via multiple pathways, including the ROS-GSK-3 $\beta$ autophagy, calcium-ERK autophagy and apoptosis, and calcium-mitochondria-caspase apoptosis pathways. In the ROS-GSK-3 $\beta$ autophagy pathway, Cd might act on mitochondria to generate ROS, which in turn results in activation of GSK-3 $\beta$ leading to autophagic cell death. In the calcium-ERK autophagy and apoptosis pathway, $\mathrm{Cd}$ acts on the endoplasmic reticulum to induce elevation of the cytosolic calcium concentration, which in turn activates ERK leading predominantly to autophagic cell death and a minor level of apoptotic cell death. In the calcium-mitochondria caspase apoptosis pathway, $\mathrm{Cd}$ induces the release of calcium by the endoplasmic reticulum and then calcium depolarizes the membrane potential of mitochondria, which in turn activates caspases 9 and 3 leading to apoptotic cell death.

Research by Wang et al., [54] points in the same direction in that it reports that treatment of mesangial cells for $24 \mathrm{~h}$ in serum-depleted medium causes both autophagy and apoptosis, in a dose dependent manner. The authors also give a demonstration that $\mathrm{Cd}$-induced autophagy is mediated directly by activation of GSK-3 $\beta$ (glycogen synthase kinase-3 $\beta$ ) [55].

In human umbilical vein endothelial cells, low concentrations of cadmium nitrate $(\leq 10 \mu \mathrm{M})$ could inhibit apoptosis induced by deprivation of serum and basic fibroblast growth factor, and promote autophagy, while apoptotic cell death was induced by higher concentrations of $\mathrm{Cd}(>20 \mu \mathrm{M})$. Findings support the notion that moderate levels of autophagy may prevent apoptosis, but excessive autophagic vacuolization also leads to cellular stress, even cell death [56].

Moreover, $\mathrm{Cd}$ induces autophagy, in a dose- and time-dependent manner, as demonstrated by the increase of LC3-II formation and the GFP-LC3 puncta cells in skin epidermal cells. Results suggest that Cd-mediated ROS generation causes PARP activation and energy depletion, and eventually induces autophagy through the activation of LKB1-AMPK signaling and the down-regulation of 
mTOR. But in this case, data reveal that Cd-induced autophagy predominantly leads to cytotoxicity and cell death [57].

Chargui et al., [58] explored the in vivo early effects of $\mathrm{Cd}$ intoxication on rat renal proximal tubule cells (PCT) using sub-toxic $\mathrm{Cd}$ doses. They showed that low $\mathrm{Cd}$ concentrations and short exposures did not affect the tubular functions nor did they induce apoptosis. In the meantime, metal accumulates in lysosomes of PCT cells, where it triggers cell proliferation and autophagy, detected by increases of LC3-II and the presence of punctuate LC3. Accumulation of Cd within the lysosomes and increases in lysosomal numbers may reflect sequestration and detoxification of this metal. In this context, autophagy, by enhancing the cell's tolerance, could provide an early adaptive mechanism avoiding apoptosis.

Conversely, one of the major causes of chronic kidney disease (CKD) is the continued exposure to low levels of $\mathrm{Cd}$. One of the causative mechanisms of chronic kidney disease is thought to be oxidative stress, therefore the involvement of mitochondria is highly plausible given that these organelles are central to the formation of excess ROS and are known to be key intracellular targets for Cd. Autophagy may remove dysfunctional mitochondria, reducing the excessive production of ROS, but if sufficient mitochondria are removed in this way then the viability of the cell cannot be maintained [59]. With regards to Cd-nephrotoxicity, the role and implication of autophagy and autophagic cell death necessitate further definition [60].

\subsubsection{Cadmium in Combination with Chromium}

Cadmium has also been used in combination with chromium $(\mathrm{Cr})$, a heavy metal that depending on its concentration induces both acute poisoning and chronic toxic effects that may contribute to carcinogenesis and the induction of degenerative diseases.

It was recently reported that autophagy is implicated in the response of hematopoietic stem/progenitor cells (HSPC) to toxic concentrations of sodium chromate and cadmium chloride, highly soluble salts releasing hexavalent chromium $(\mathrm{Cr}[\mathrm{VI}])$ and cadmium $(\mathrm{Cd})$ cations, respectively, two of the best known toxic and carcinogenic heavy metals [61,62]. Results suggest that cells exposed to sub-toxic $(0.1 \mu \mathrm{M})$ and toxic $(10 \mu \mathrm{M})$ concentrations of each of the two cations (co-treatment) show autophagic morphologies (as autophagosomes/autophagolysosomes) and do not show the morphological hallmarks of apoptosis, contrary to what was reported for similar treatments in myelogenous leukemia and promyelocytic leukemia cell lines as well as peripheral blood mononuclear cells [63].

Autophagy may lead to cell death if carried out excessively, but may also act as a temporary survival pathway in cells under stress, mitigating metal-induced toxicity, delaying or preventing apoptosis, contributing to the conservation of tissue renewal capability, perhaps because removal of damaged mitochondria may keep cells under the threshold of caspase activity needed to trigger death. It may be that in the hematopoietic lineage, autophagy and apoptosis are both involved in the response to $\mathrm{Cr}(\mathrm{VI})$ - and $\mathrm{Cd}$-induced toxic stress, and the molecular switch between the two pathways could be regulated according to differentiation.

\subsubsection{Effects of Cadmium on Aquatic Invertebrates}

Heavy metal persistence and accumulation in biota is widespread in the aquatic environment. Aquatic invertebrates are known to accumulate high levels of heavy metals in their tissues and yet 
survive in polluted environments. Their tolerance of high metal content in tissues probably depends on the ability of these organisms to regulate heavy metal cation concentrations inside the cell and to accumulate excess metal in non-toxic forms $[64,65]$.

Sub-lethal effects of $\mathrm{Cd}$ on population growth rate, gametogenesis and embryogenesis have been described in a variety of aquatic invertebrate organisms, such as sponges, molluscs, crustaceans, echinoderms, some of which are considered as good bio-indicators to assess the contamination of the aquatic environment. Therefore, the effects of $\mathrm{Cd}$ on these organisms have been studied, examining: accumulation of metal in adult tissues, embryonic development perturbation, stress protein induction, expression of detoxification genes, apoptosis and related pathways [49].

There is increasing evidence of $\mathrm{Cd}$ accumulation in the digestive and excretory organs of some benthonic invertebrates. Very high concentrations of the metal were found in the digestive gland of a few species of Antarctic molluscs [66] and in the digestive gland and kidney of the mussel Crenomytilus grayanus [67], suggesting again that food is the primary pathway for $\mathrm{Cd}$ bio-accumulation and that the digestive gland plays a major role in the subsequent storage and detoxification. In the renal tissue of Antarctic bivalve Laternula elliptica the high levels of $\mathrm{Cd}$ and its bio-accumulation can be a probable advantage for environmental adaptation in the Antarctic marine environment [68].

Responses to $\mathrm{Cd}$ exposure are well documented for Ruditapes decussatus. In this bivalve mollusc, the metal is mainly accumulated in the gill following transport to the digestive gland, where it is continuously accumulated. A paper by Chora et al., [69] shows that $\mathrm{Cd}$ exposure causes changes in protein expression in the gill and digestive gland. The tissues exhibited different protein expression due to their different functions in molluscs. An overall decrease of proteins was detected in both treated tissues. The authors suggest that lysosomal autophagy could explain this decrease of proteins and at the same time it could be considered a survival strategy, but there is no experimental evidence that the autophagic process actually occurs.

Recently it has been suggested that autophagy appears to be a common target for many environmental pollutants, as lysosomes accumulate many toxic metals and organic xenobiotics, which perturb normal function and damage the lysosomal membrane.

At present, the study on the role of autophagy in aquatic organisms exposed to heavy metals is a new emerging research field.

\subsubsection{Stress Response in Cd-Exposed Sea Urchin Embryos}

Sea urchins are an ancient group (at least 450 million years old) of Class Echinoidea in the Phylum Echinodermata, with hundreds of species known in the world's oceans. Since about 1880, the eggs and sperm of sea urchins have been used for the study of fertilization, the metabolic activation of development and gene regulatory mechanisms governing embryogenesis. In addition, the genome of one sea urchin, Strongylocentrotus purpuratus, is known, and the size is $\sim 800 \mathrm{Mb}$, compared to the human genome of $\sim 3,200 \mathrm{Mb}$ [70]. This aspect permitted to explore whether parts of the vertebrate toolkit are also present in invertebrate deuterostomes, allowing ascertaining a lineage-specific evolution of various molecular networks. 
This marine organism directly interacts with its environment and is susceptible to effects of several aquatic contaminants. Several molecular mechanisms can be adopted as a defense mechanism against any environmental chemical, physical and mechanical stress, in an attempt to preserve the developmental program. The sea urchin embryo represents a suitable model system to investigate the adaptive response of cells exposed to stress during development and differentiation [71,72].

Contrary to the view that embryos and larvae are the most fragile stages of life, development is stable under real-world conditions. Early cleavage embryos are prepared for environmental alterations by having high levels of cellular defenses already present in the egg before fertilization. Later in development, adaptive responses to the environment either buffer stress or produce alternative developmental phenotypes [73].

The chemicals of anthropogenic origin are of considerable interest for their ability to induce the activation of defense systems or interrupt the developmental program. $\mathrm{Cd}$ is a known stress agent and in some cases, as well as inducing apoptosis, is able to trigger autophagy. It is currently well accepted that autophagic cell death represents a separate route of programmed cell death significantly different from conventional apoptosis, but autophagy also represent a program of cell survival [74].

However, at present, there are few studies on the role of autophagy during development and on the putative protective function that it has in embryos exposed to stress.

It was previously demonstrated that subacute/sublethal concentrations of $\mathrm{Cd}$ induce, during development of sea urchin embryos, morphological abnormalities, activation of specific stress proteins (HSPs), expression of metallothioneins and apoptosis, in a dose/time-dependent manner [75,76]. Essentially, Cd exerts its toxic action in the long term: Embryos accumulate the metal in the cells, as demonstrated by Atomic Absorption Spectrometry. It has been suggested that survival systems adopted during embryonic development of sea urchins can operate in tandem through a putative crosstalk [77,78].

\subsubsection{Analyzing Autophagy in Cd-Exposed Sea Urchin Embryos}

Recently, autophagy activation in sea urchin embryos has been reported for the first time. The purpose of this study was to investigate whether autophagy occurs in Paracentrotus lividus embryos, a species of sea urchin very common in the Mediterranean Sea, both in physiological development and in response to stress, as a defense strategy after exposure to $\mathrm{Cd}$, for the survival and maintenance of the developmental program.

Several experimental approaches were used to detect autophagy: identification of autophagolysosomes, by acidotropic dyes such as neutral red and acridine orange; immunodetection of LC3-II, by Western blot and immunofluorescence in situ analyses.

Results demonstrated that autophagy is a molecular process present in sea urchin embryos at a higher level after $\mathrm{Cd}$ treatment and at a basal level during physiological development. Specifically, the experiments revealed a higher level of autophagosomes for embryos treated for 18 hours with $1 \mathrm{mM} \mathrm{CdCl}_{2}$, compared with controls [74]. It should be noted that after 24 hours of treatment, embryos show a lower level of autophagosomes, probably because the apoptotic process becomes significant, as previously demonstrated [72,78]. In fact, immunodetection of LC3-II shows that it is mainly present in embryos treated for 18 hours rather than for 24 hours; in addition, the LC3 signal is largely cytosolic in control embryos, while it reveals a "punctuate" localization in embryos Cd-treated (Figure 1). 
Figure 1. Detection by immunofluorescence of LC3 protein on whole-mount embryos of sea urchin. Equatorial optical sections captured by confocal laser scanning microscopy. In green, LC3 protein detection; in red, nuclei stained with propidium iodide. (A) Control embryo, after $18 \mathrm{~h}$ of growth; (B) Cd-treated embryo for $18 \mathrm{~h}$; (C) Control embryo, after 24 h of growth; (D) Cd-treated embryo for 24 h; (E, F) Enlargements of a section of (B, D), respectively. $\mathrm{Bar}=50 \mu \mathrm{m}$.
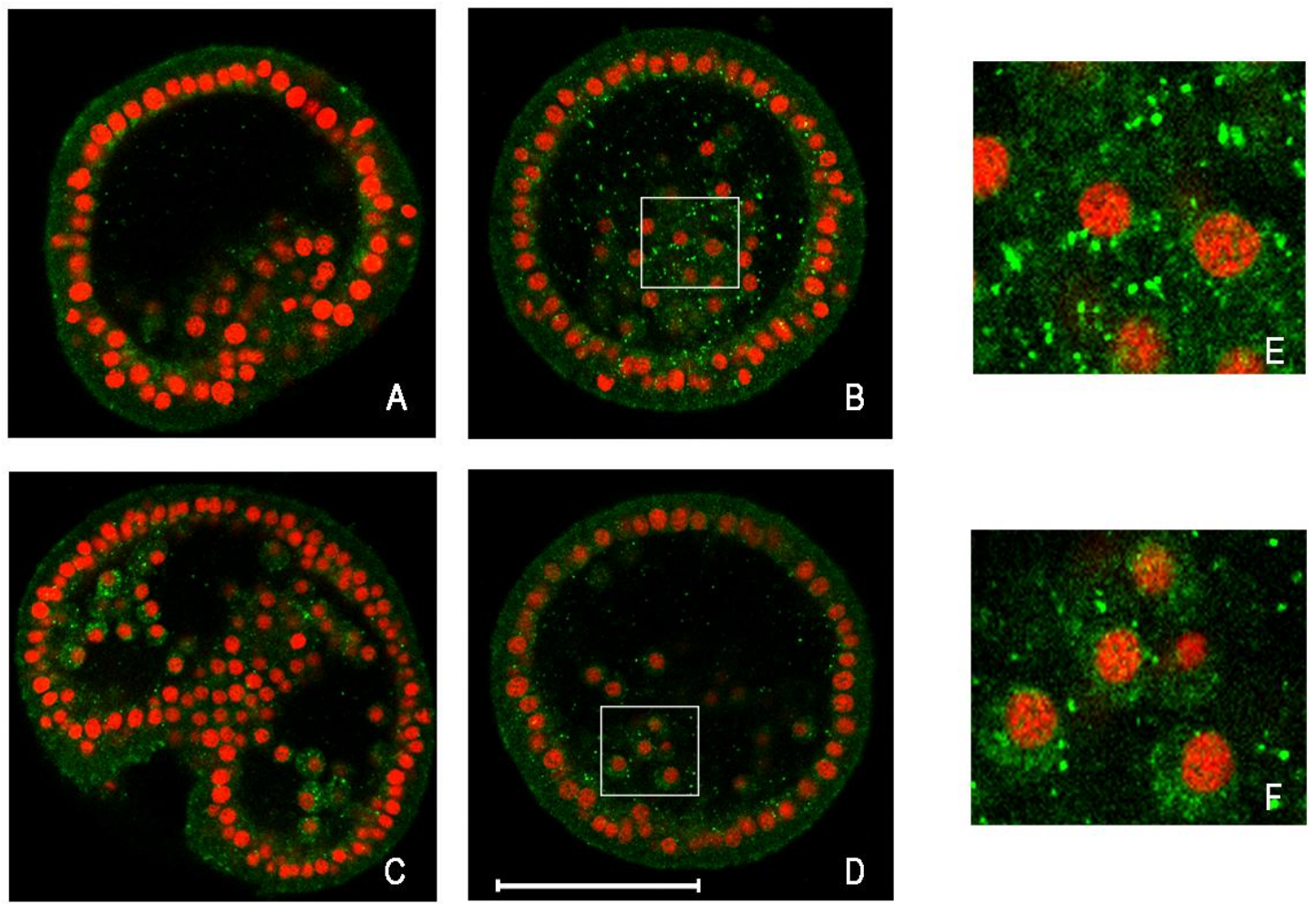

The results obtained suggest that probably the first defense strategies put in place by the embryo against stress by $\mathrm{Cd}$, metallothioneins and HSPs, are able to produce a detoxifying and antioxidant effect that is not always sufficient to block the action of the toxic metal, depending on the extent of cell damage $[79,80]$. In such circumstances the mechanisms of programmed cell death, such as apoptosis, may be triggered [81].

The high level of autophagy activation at a specific time seems to be critical because, although it is a normal mechanism of clearance, in some extreme cases it reaches high levels, indicating the possibility of modulating the activation and representing the high plasticity of this molecular mechanism for the survival of embryonic cells. Figure 2 shows a hypothetical model of reconstruction of the events that occur in embryos exposed to $1 \mathrm{mM} \mathrm{CdCl}_{2}$ for 24 hours, or exposed to lower $\mathrm{Cd}$ concentrations for longer periods of time. In this reconstruction, autophagy can be activated in a specific period of time, after HSPs and metallothionein induction and before apoptosis triggering, in a last attempt to safeguard the developmental program. However, the persistence of stress inevitably leads to apoptosis.

Sea urchin embryos continuously exposed to $\mathrm{Cd}$ provide a suitable model to study the role of autophagy in Cd-stress responses [82].

Representative data from experiments performed in different model systems are reported in Table 2. 
Figure 2. Diagram showing an overview of the most representative cellular, biochemical, and molecular events activated as defense strategies in embryos and larvae of $P$. lividus at different times post fertilization and various concentrations of $\mathrm{CdCl}_{2}$.

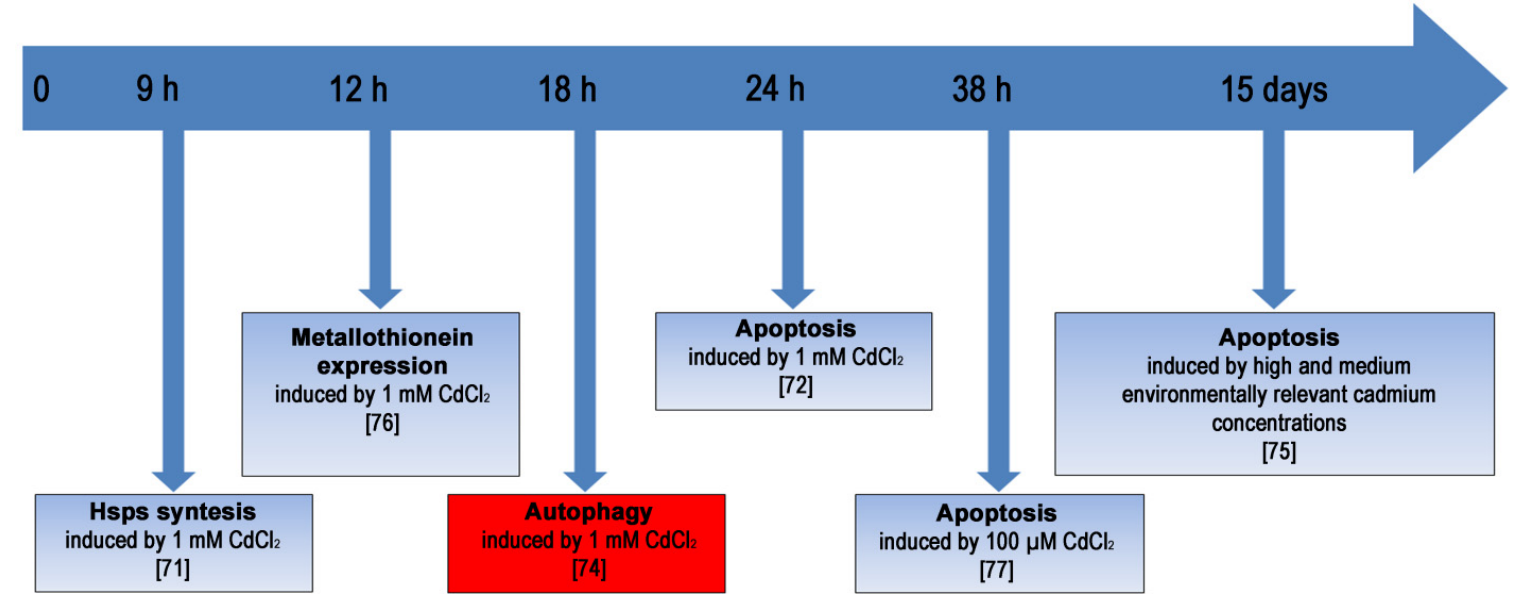

Table 2. Cadmium concentration and induced cellular response with respect to autophagy.

\begin{tabular}{|c|c|c|c|}
\hline $\begin{array}{l}\text { Cd compounds } \\
\text { (concentrations) }\end{array}$ & Autophagic effects & $\begin{array}{c}\text { Experimental } \\
\text { model }\end{array}$ & References \\
\hline $\mathrm{CdCl}_{2}(3-24 \mu \mathrm{M})$ & $\begin{array}{l}\text { calcium-mediated autophagy and } \\
\text { apoptosis, through the ERK-dependent } \\
\text { and mitochondria-caspase signaling } \\
\text { pathways, respectively }\end{array}$ & $\begin{array}{l}\text { mouse kidney } \\
\text { mesangial cells }\end{array}$ & {$[54]$} \\
\hline $\mathrm{CdCl}_{2}(1-10 \mu \mathrm{M})$ & $\begin{array}{l}\text { autophagy that leads to cytotoxicity, as } \\
\text { cell death mechanism; detected by an } \\
\text { accumulation of autofagosomes and } \\
\text { increased levels of LC3-II }\end{array}$ & $\begin{array}{l}\text { mouse epidermal } \\
\text { cell line }\end{array}$ & {$[57]$} \\
\hline $\begin{array}{l}\mathrm{Cd}\left(\mathrm{NO}_{3}\right)_{2}(1-10 \mu \mathrm{M}) \\
\mathrm{Cd}\left(\mathrm{NO}_{3}\right)_{2}(>20 \mu \mathrm{M})\end{array}$ & $\begin{array}{l}\text { autophagy, as cell survival mechanism, } \\
\text { detected by an accumulation of } \\
\text { autolysosomes and increased levels of } \\
\text { LC3-II;apoptotic cell death }\end{array}$ & $\begin{array}{l}\text { human vascular } \\
\text { endothelial cells }\end{array}$ & {$[56]$} \\
\hline $\begin{array}{l}\mathrm{CdCl}_{2}(0.3 \mathrm{mg} / \mathrm{kg} \text { body } \\
\text { mass } / 1,3 \text { and } 5 \text { days of } \\
\text { intoxication })\end{array}$ & autophagy, as cell survival mechanism & rat kidney & {$[58]$} \\
\hline $\begin{array}{l}\mathrm{CdCl}_{2}(1 \mathrm{mM} \text { for } 18 \text { hours } \\
\text { of exposure }) \\
\mathrm{CdCl}_{2}(1 \mathrm{mM} \text { for } 24 \text { hours } \\
\text { of exposure })\end{array}$ & $\begin{array}{l}\text { autophagy as a survival mechanism } \\
\text { detected by an accumulation of } \\
\text { autolysosomes and increased levels of } \\
\text { LC3-II;Apoptotic cell death }\end{array}$ & $\begin{array}{l}\text { sea urchin } \\
\text { embryos }\end{array}$ & {$[74]$} \\
\hline
\end{tabular}

\section{Conclusions}

Heavy metals and metalloids represent two of the most dangerous pollutants, and, due to their bioaccumulation, have been proven to be toxic both for human and environmental health. The adaptation to handle stress by metals through removal and recycling of damaged proteins and organelles may have been critical throughout evolution in biota naturally exposed to fluctuating levels of these toxicants [61]. 
Great progress has been made in recent years in understanding various facets of autophagy but there is still much need to understand the effects between exposure to various environmental factors and autophagy. This review shows that exposition to As and Cd compounds induces changes in autophagic response that are differently associated with specific disease. Identification of critical exposure to these compounds, related to the activation of autophagy, could help to identify analogous pathways triggered by potential useful drugs in therapy.

The research summarized herein shows that autophagy and apoptosis may be used as an alternative and/or combined method by cells exposed to toxic concentrations of heavy metals or metalloids. However autophagy is also a process of cell survival that confronts the cell with the choice to live or to die. One possibility is that autophagy could represent a cell survival mechanism where cellular damage is not too extensive, or may lead to cell death wher the damage/stress is irreversible; in this last case it acts in association with apoptosis or with an independent pathway.

The relationship between autophagy and apoptosis and the antitumor effects still remain obscure. The multifaceted relation of autophagy with tumorigenesis and studies supporting a role for autophagy in both tumor-suppression and tumor-progression are still needed. However it is undeniable that the use of autophagy induction for cancer treatment presents novel therapeutic opportunities. As discussed above, induction of autophagic cell death by arsenic trioxide provides promising new opportunities for the treatment of resistant malignant gliomas, and it is now in clinical trials. The main challenge today is to determine when to apply each drug, depending on the biological understanding of the status of the cancer cells [7].

With regard to Cd-exposed cells, the role of autophagy in influencing cell survival or death is controversial and dependent on the exposure conditions. It was reported that autophagy did not protect cells from Cd-induced toxicity [54], but a recent investigation supported a protective effect of autophagy on Cd-induced cell death [83]. In fact, as observed for $\mathrm{Cd}$ stress, depending on the concentration and exposure time, this metal may induce cell survival (for lower expositions) or apoptosis (for elevated expositions).

Given the relevance of the tumor suppressor role for autophagy, an understanding of the mechanisms regulating the crosstalk with cell proliferation and differentiation both in embryogenesis and adulthood is an essential goal for researchers.

It is to be highlighted, owing to the importance of autophagy in the turnover of cellular components, that this process is expected to have a crucial role in the events occurring during embryogenesis. Developing cells, in fact, have to adapt constantly and quickly to both intrinsic and environmental changes in order to survive and to differentiate. During this process, the damaged and unnecessary organelles need to be promptly cleared and the cell shape needs to be modified to adapt to new functions. The exact mechanisms by which autophagy contributes to embryonic phenotypes in multicellular eukaryotes are not clear. However, both in invertebrate and vertebrate organisms, it is generally thought that autophagy plays an essential dual role both in the adaptation to stress and starvation phenomena occurring during morphogenesis and in cell elimination, in concert with the apoptotic machinery [84]. In addition, autophagic cell death appears to precede apoptosis when massive cell elimination is required during development. To fully understand the molecular responses induced by heavy metals or metalloids it is appropriate to incorporate new biomarkers with high 
sensitivity and specificity, and autophagy seems be a good marker of toxicity since it is a specific mechanism conserved from yeast to humans.

In this contest, the sea urchin embryo is one of the most suitable organisms to extend the observations on autophagy made in budding yeast, plants, and mammalian cells and to ask questions about the control of autophagy both during physiological development and in stress condition, as we recently have reported in the guidelines for the use and interpretation of assays for monitoring autophagy [82].

In conclusion, autophagy may represent a key evolutionarily conserved response to toxic metals/metalloids. The relationships between autophagy and apoptosis and their molecular regulation, need to be explored in connection with exposure to specific toxicants. Although autophagy is aimed primarily at cell survival or at cell death, it is possible to remain a subject of debate for some time, for the immediate future the therapeutic uses of autophagy inducers and inhibitors in modulating both its survival and death-promoting properties show promise and continue to be actively explored. On the other hand, it may enhance cell death by a variety of mechanisms, thus leading to tissue pathology and organ damage. In either case, the outcome for a cell exposed to toxicants is dependent not only upon the duration and level of exposure, but also on other factors intrinsic to the cell itself, and its current metabolic state.

Finally, autophagy is one of a wide range of strategies that can be activated in response to heavy metal and metalloid toxicity.

\section{Acknowledgments}

The authors are grateful to Prof. Claudio Luparello for critical revision. The first author has been the recipient of a Doctoral fellowship from the University of Palermo.

\section{References}

1. Xie, Z.; Klionsky, D.J. Autophagosome formation: Core machinery and adaptations. Nat. Cell Biol. 2007, 9, 1102-1109.

2. Klionsky, D.J.; Abeliovich, H.; Agostinis, P.; Agrawal, D.K.; Aliev, G.; Askew, D.S.; Baba, M.; Baehrecke, E.H.; Bahr, B.A.; Ballabio, A.; et al. Guidelines for the use and interpretation of assays for monitoring autophagy in higher eukaryotes. Autophagy 2008, 4, 151-175.

3. Scarlatti, F.; Granata, R.; Meijer, A.J.; Codogno, P. Does autophagy have a license to kill mammalian cells? Cell Death Differ. 2009, 16, 12-20.

4. Adastra, K.L.; Chi, M.M.; Riley, J.K.; Moley, K.H. A differential autophagic response to hyperglycemia in the developing murine embryo. Reproduction 2011, 141, 607-615.

5. Kroemer, G.; Galluzzi, L.; Vandenabeele, P.; Abrams, J.; Alnemri, E.S.; Baehrecke, E.H.; Blagosklonny, M.V.; El-Deiry, W.S.; Golstein, P.; Green, D.R.; et al. Classification of cell death: Recommendations of the Nomenclature Committee on Cell Death 2009. Cell Death Differ. 2009, 16, 3-11.

6. Yu, L.; Lenardo, M.J.; Baehrecke, E.H. Autophagy and caspases: A new cell death program. Cell Cycle 2004, 3, 1124-1126. 
7. Eisenberg-Lerner, A.; Kimchi, A. The paradox of autophagy and its implication in cancer etiology and therapy. Apoptosis 2009, 14, 376-391.

8. Vazquez-Martin, A.; Oliveras-Ferraros, C.; Menendez, J.A. Autophagy facilitates the development of breast cancer resistance to the anti-HER2 monoclonal antibody trastuzumab. PLoS One 2009, 4, e6251.

9. Song, J.; Qu, Z.; Guo, X.; Zhao, Q.; Zhao, X.; Gao, L.; Sun, K.; Shen, F.; Wu, M.; Wei, L. Hypoxia-induced autophagy contributes to the chemoresistance of hepatocellular carcinoma cells. Autophagy 2009, 5, 1131-1144.

10. Bellodi, C.; Lidonnici, M.R.; Hamilton, A.; Helgason, G.V.; Soliera, A.R.; Ronchetti, M.; Galavotti, S.; Young, K.W.; Selmi, T.; Yacobi, R.; et al. Targeting autophagy potentiates tyrosine kinase inhibitor-induced cell death in Philadelphia chromosome-positive cells, including primary CML stem cells. J. Clin. Invest. 2009, 119, 1109-1123.

11. Apel, A.; Zentgraf, H.; Büchler, M.W.; Herr, I. Autophagy-A double-edged sword in oncology. Int. J. Cancer 2009, 125, 991-995.

12. Yue, Z.; Jin, S.; Yang, C.; Levine, A.J.; Heintz, N. Beclin 1, an autophagy gene essential for early embryonic development, is a haploinsufficient tumor suppressor. Proc. Natl. Acad. Sci. USA 2003, 100, 15077-15082.

13. Qu, X.; Yu, J.; Bhagat, G.; Furuya, N.; Hibshoosh, H.; Troxel, A.; Rosen, J.; Eskelinen, E.L.; Mizushima, N.; Ohsumi, Y.; et al. Promotion of tumorigenesis by heterozygous disruption of the beclin 1 autophagy gene. J. Clin. Invest. 2003, 112, 1809-1820.

14. Arico, S.; Petiot, A.; Bauvy, C.; Dubbelhuis, P.F.; Meijer, A.J.; Codogno, P.; Ogier-Denis, E. The tumor suppressor PTEN positively regulates macroautophagy by inhibiting the phosphatidylinositol 3-kinase/protein kinase B pathway. J. Biol. Chem. 2001, 276, 35243-35246.

15. Crighton, D.; Wilkinson, S.; O’Prey, J.; Syed, N.; Smith, P.; Harrison, P.R.; Gasco, M.; Garrone, O.; Crook, T.; Ryan, K.M. DRAM, a p53-induced modulator of autophagy, is critical for apoptosis. Cell 2006, 126, 121-134.

16. Maiuri, M.C.; Le Toumelin, G.; Criollo, A.; Rain, J.C.; Gautier, F.; Juin, P.; Tasdemir, E.; Pierron, G.; Troulinaki, K.; et al. Functional and physical interaction between Bcl-X(L) and a BH3-like domain in Beclin-1. EMBO J. 2007, 26, 2527-2539.

17. Luo, S.; Rubinsztein, D.C. Apoptosis blocks Beclin 1-dependent autophagosome synthesis: An effect rescued by Bcl-xL. Cell Death Differ. 2010, 17, 268-277.

18. Sarbassovdos, D.; Ali, S.M.; Sabatini, D.M. Growing roles for the mTOR pathway. Curr. Opin. Cell Biol. 2005, 17, 596-603.

19. Gozuacik, D.; Kimchi, A. Autophagy as a cell death and tumor suppressor mechanism. Oncogene 2004, 23, 2891-2906.

20. Liang, X.H.; Jackson, S.; Seaman, M.; Brown, K.; Kempkes, B.; Hibshoosh, H.; Levine, B. Induction of autophagy and inhibition of tumorigenesis by beclin 1. Nature 1999, 402, 672-676.

21. Choi, K.S. Autophagy and cancer. Exp. Mol. Med. 2012, 29, 109-120.

22. Scheifler, R.; Coeurdassier, M.; Morilhat, C.; Bernard, N.; Faivre, B.; Flicoteaux, P.; Giraudoux, P.; Noël, M.; Piotte, P.; Rieffel, D.; et al. Lead concentrations in feathers and blood of common blackbirds (Turdus merula) and in earthworms inhabiting unpolluted and moderately polluted urban areas. Sci. Total Environ. 2006, 371, 197-205. 
23. Jha, A.N.; Noditi, M.; Nilsson, R.; Natarajan, A.T. Genotoxic effects of sodium arsenite on human cells. Mutat. Res. 1992, 284, 215-221.

24. Tice, R.R.; Yager, J.W.; Andrews, P.; Crecelius, E. Effect of hepatic methyl donor status on urinary excretion and DNA damage in $\mathrm{B} 6 \mathrm{C} 3 \mathrm{~F} 1$ mice treated with sodium arsenite. Mutat. Res. 1997, 386, 315-334.

25. Miller, W.H.; Schipper, H.M.; Lee, J.S.; Singer, J.; Waxman, S. Mechanisms of action of arsenic trioxide. Cancer Res. 2002, 62, 3893-3903.

26. Miller, W.H., Jr. Molecular targets of arsenic trioxide in malignant cells. Oncologist 2002, 7, 14-19.

27. Goussetis, D.J.; Altman, J.K.; Glaser, H.; McNeer, J.L.; Tallman, M.S.; Platanias, L.C. Autophagy is a critical mechanism for the induction of the antileukemic effects of arsenic trioxide. J. Biol. Chem. 2010, 285, 29989-29997.

28. Kanzawa, T.; Zhang, L.; Xiao, L.; Germano, I.M.; Kondo, Y.; Kondo, S. Arsenic trioxide induces autophagic cell death in malignant glioma cells by upregulation of mitochondrial cell death protein BNIP3. Oncogene 2005, 24, 980-991.

29. Isakson, P.; Bjørås, M.; Bøe, S.O.; Simonsen, A. Autophagy contributes to therapy-induced degradation of the PML/RARA oncoprotein. Blood 2010, 116, 2324-2331.

30. Qian, W.; Liu, J.; Jin, J.; Ni, W.; Xu, W. Arsenic trioxide induces not only apoptosis but also autophagic cell death in leukemia cell lines via up-regulation of Beclin-1. Leuk. Res. 2007, 31, 329-339.

31. Zhu, X.H.; Shen, Y.L.; Jing, Y.K.; Cai, X.; Jia, P.M.; Huang, Y.; Tang, W.; Shi, G.Y.; Sun, Y.P.; Dai, J.; et al. Apoptosis and growth inhibition in malignant lymphocytes after treatment with arsenic trioxide at clinically achievable concentrations. J. Natl. Cancer Inst. 1999, 91, 772-778.

32. Sturlan, S.; Baumgartner, M.; Roth, E.; Bachleitner-Hofmann, T. Docosahexaenoic acid enhances arsenic trioxide-mediated apoptosis in arsenic trioxide-resistant HL-60 cells. Blood 2003, 101, 4990-4997.

33. Glienke, W.; Chow, K.U.; Bauer, N.; Bergmann, L. Down-regulation of wt 1 expression in leukemia cell lines as part of apoptotic effect in arsenic treatment using two compounds. Leuk. Lymphoma 2006, 47, 1629-1638.

34. Charoensuk, V.; Gati, W.P.; Weinfeld, M.; Le, X.C. Differential cytotoxic effects of arsenic compounds in human acute promyelocytic leukemia cells. Toxicol. Appl. Pharmacol. 2009, 239, 64-70.

35. Yang, Y.P.; Liang, Z.Q.; Gao, B.; Jia, Y.L.; Qin, Z.H. Dynamic effects of autophagy on arsenic trioxide-induced death of human leukemia cell line HL60 cells. Acta Pharmacol. Sin. 2008, 29, 123-134.

36. Azad, M.B.; Chen, Y.; Gibson, S.B. Regulation of autophagy by reactive oxygen species (ROS): Implications for cancer progression and treatment. Antioxid. Redox Signal. 2009, 11, 777-790.

37. Scherz-Shouval, R.; Shvets, E.; Elazar, Z. Oxidation as a post-translational modification that regulates autophagy. Autophagy 2007, 3, 371-373.

38. Gibson, S.B. A matter of balance between life and death: Targeting reactive oxygen species (ROS)-induced autophagy for cancer therapy. Autophagy 2010, 6, 835-837.

39. Kroemer, G.; Levine, B. Autophagic cell death: The story of a misnomer. Nat. Rev. Mol. Cell Biol. 2008, 9, 1004-1010. 
40. Raffoul, F.; Campla, C.; Nanjundan, M. SnoN/SkiL, a TGF $\beta$ signaling mediator: A participant in autophagy induced by arsenic trioxide. Autophagy 2010, 6, 955-957.

41. Bolt, A.M.; Byrd, R.M.; Klimecki, W.T. Autophagy is the predominant process induced by arsenite in human lymphoblastoid cell lines. Toxicol. Appl. Pharmacol. 2010, 244, 366-373.

42. Bolt, A.M.; Douglas, R.M.; Klimecki, W.T. Arsenite exposure in human lymphoblastoid cell lines induces autophagy and coordinated induction of lysosomal genes. Toxicol. Lett. 2010, 199, 153-159.

43. Han, M.H.; Lee, W.S.; Lu, J.N.; Yun, J.W.; Kim, G.; Jung, J.M.; Kim, G.Y.; Lee, S.J.; Kim, W.J.; Choi, Y.H. Tetraarsenic Hexoxide Induces Beclin-1-Induced Autophagic Cell Death as well as Caspase-Dependent Apoptosis in U937 Human Leukemic Cells. Evid.-Based Complement Altern. Med. 2012, 2012, doi:10.1155/2012/201414.

44. Cheng, T.J.; Wang, Y.J.; Kao, W.W.; Chen, R.J.; Ho, Y.S. Protection against arsenic trioxide-induced autophagic cell death in U118 human glioma cells by use of lipoic acid. Food Chem. Toxicol. 2007, 45, 1027-1038.

45. Huang, Y.C.; Hung, W.C.; Chen, W.T.; Yu, H.S.; Chai, C.Y. Sodium arsenite-induced DAPK promoter hypermethylation and autophagy via ERK1/2 phosphorylation in human uroepithelial cells. Chem. Biol. Interact. 2009, 181, 254-262.

46. Chiu, H.W.; Ho, S.Y.; Guo, H.R.; Wang, Y.J. Combination treatment with arsenic trioxide and irradiation enhances autophagic effects in U118-MG cells through increased mitotic arrest and regulation of PI3K/Akt and ERK1/2 signaling pathways. Autophagy 2009, 5, 472-483.

47. Chiu, H.W.; Lin, J.H.; Chen, Y.A.; Ho, S.Y.; Wang, Y.J. Combination treatment with arsenic trioxide and irradiation enhances cell-killing effects in human fibrosarcoma cells in vitro and in vivo through induction of both autophagy and apoptosis. Autophagy 2010, 6, 353-365.

48. Larson, J.L.; Somji, S.; Zhou, X.D.; Sens, M.A.; Garrett, S.H.; Sens, D.A.; Dunlevy, J.R. Beclin-1 expression in normal bladder and in $\mathrm{Cd} 2+$ and $\mathrm{As} 3+$ exposed and transformed human urothelial cells (UROtsa). Toxicol. Lett. 2010, 195, 15-22.

49. Roccheri, M.C.; Matranga, V. Cellular, Biochemical and Molecular Effects of Cadmium on Marine Invertebrates: Focus on Paracentrotus lividus Sea Urchin Development. In Cadmium in the Environment; Parvau, R.G., Ed.; Nova Science Publishers: New York, NY, USA, 2010; pp. 337-366.

50. Achanzar, W.E.; Diwan, B.A.; Liu, J.; Quader, S.M.; Webber, M.M.; Waalkes, M.P. Cadmium-induced malignant transformation of human prostate epithelial cells. Cancer Res. 2001, 61, 455-458.

51. Joseph, P. Mechanisms of cadmium carcinogenesis. Toxicol. Appl. Pharmacol. 2009, 238, 272-279.

52. Templeton, D.M.; Liu, Y. Multiple roles of cadmium in cell death and survival. Chem. Biol. Interact. 2010, 188, 267-275.

53. Yang, L.Y.; Wu, K.H.; Chiu, W.T.; Wang, S.H.; Shih, C.M. The cadmium-induced death of mesangial cells results in nephrotoxicity. Autophagy 2009, 5, 571-572.

54. Wang, S.H.; Shih, Y.L.; Ko, W.C.; Wei, Y H.; Shih, C.M. Cadmium-induced autophagy and apoptosis are mediated by a calcium signaling pathway. Cell. Mol. Life Sci. 2008, 65, 3640-3652.

55. Wang, S.H.; Shih, Y.L.; Kuo, T.C.; Ko, W.C.; Shih, C.M. Cadmium toxicity toward autophagy through ROS-activated GSK-3beta in mesangial cells. Toxicol. Sci. 2009, 108, 124-131. 
56. Dong, Z.; Wang, L.; Xu, J.; Li, Y.; Zhang, Y.; Zhang, S.; Miao, J. Promotion of autophagy and inhibition of apoptosis by low concentrations of cadmium in vascular endothelial cells. Toxicol. In Vitro 2009, 23, 105-110.

57. Son, Y.O.; Wang, X.; Hitron, J.A.; Zhang, Z.; Cheng, S.; Budhraja, A.; Ding, S.; Lee, J.C.; Shi, X. Cadmium induces autophagy through ROS-dependent activation of the LKB1-AMPK signaling in skin epidermal cells. Toxicol. Appl. Pharmacol. 2011, 255, 287-296.

58. Chargui, A.; Zekri, S.; Jacquillet, G.; Rubera, I.; Ilie, M.; Belaid, A.; Duranton, C.; Tauc, M.; Hofman, P.; Poujeol, P.; et al. Cadmium-induced autophagy in rat kidney: An early biomarker of subtoxic exposure. Toxicol. Sci. 2011, 121, 31-42.

59. Sansanwal, P.; Li, L.; Hsieh, S.C.; Sarwal, M.M. Insights into novel cellular injury mechanisms by gene expression profiling in nephropathic cystinosis. J. Inherit. Metab. Dis. 2010, 33, 775-786.

60. Gobe, G.; Crane, D. Mitochondria, reactive oxygen species and cadmium toxicity in the kidney. Toxicol. Lett. 2010, 198, 49-55.

61. Di Gioacchino, M.; Petrarca, C.; Perrone, A.; Farina, M.; Sabbioni, E.; Hartung, T.; Martino, S.; Esposito, D.L.; Lotti, L.V.; Mariani-Costantini, R. Autophagy as an ultrastructural marker of heavy metal toxicity in human cord blood hematopoietic stem cells. Sci. Total Environ. 2008, 392, $50-58$.

62. Di Gioacchino, M.; Petrarca, C.; Perrone, A.; Martino, S.; Esposito, D.L.; Lotti, L.V.; Mariani-Costantini, R. Autophagy in hematopoietic stem/progenitor cells exposed to heavy metals: Biological implications and toxicological relevance. Autophagy 2008, 4, 537-539.

63. Bagchi, D.; Joshi, S.S.; Bagchi, M.; Balmoori, J.; Benner, E.J.; Kuszynski, C.A.; Stohs, S.J. Cadmium- and chromium-induced oxidative stress, DNA damage, and apoptotic cell death in cultured human chronic myelogenous leukemic K562 cells, promyelocytic leukemic HL-60 cells, and normal human peripheral blood mononuclear cells. J. Biochem. Mol. Toxicol. 2000, 14, 33-41.

64. Viarengo, A. Heavy Metal in Marine Invertebrates: Mechanisms of Regulation and Toxicity at the Cellular Level. In Aquatic Sciences; Birkhäuse: Basel, Switzerland, 1989; Volume 1, pp. 295-317.

65. Rainbow, P.S. Trace metal concentrations in aquatic invertebrates: Why and so what? Environ. Pollut. 2002, 120, 497-507.

66. Nigro, M.; Regoli, F.; Rocchi, R.; Orlando, E. Heavy metals in Antarctic molluscs. In Antarctic Communities: Species, Structure and Survival; Battaglia, B., Valencia, J., Walton, D.W.H., Eds.; Cambridge University Press: Cambridge, UK, 1997; pp. 409-412.

67. Podgurskaya, O.V.; Kavun, V.Y. Cadmium concentration and subcellular distribution in organs of the mussel Crenomytilus grayanus from upwelling regions of Okhotsk Sea and Sea of Japan. Arch. Environ. Contam. Toxicol. 2006, 51, 567-572.

68. Rodrigues, E.; da Silva Santos, M.R.; Rodrigues, E., Jr.; Gannabathula, S.V.; Passeri Lavrado, H. Arginine metabolism of the Antarctic Bivalve Laternula elliptica (King \& Broderip, 1831): An ecophysiological approach. Polar Biol. 2009, 32, 691-702.

69. Chora, S.; Starita-Geribaldi, M.; Guigonis, J.M.; Samson, M.; Roméo, M.; Bebianno, M.J. Effect of cadmium in the clam Ruditapes decussatus assessed by proteomic analysis. Aquat. Toxicol. 2009, 94, 300-308.

70. Vacquier, V.D. Laboratory on sea urchin fertilization. Mol. Reprod. Dev. 2011, 78, 553-564. 
71. Roccheri, M.C.; Agnello, M.; Bonaventura, R.; Matranga, V. Cadmium induces the expression of specific stress proteins in sea urchin embryos. Biochem. Biophys. Res. Commun. 2004, 321, 80-87.

72. Agnello, M.; Filosto, S.; Scudiero, R.; Rinaldi, A.M.; Roccheri, M.C. Cadmium induces an apoptotic response in sea urchin embryos. Cell Stress Chaperones 2007, 12, 44-50.

73. Hamdoun, A.; Epel, D. Embryo stability and vulnerability in an always changing world. Proc. Natl. Acad. Sci. USA 2007, 104, 1745-1750.

74. Chiarelli, R.; Agnello, M.; Roccheri, M.C. Sea urchin embryos as a model system for studying autophagy induced by cadmium stress. Autophagy 2011, 7, 1028-1034.

75. Filosto, S.; Roccheri, M.C.; Bonaventura, R.; Matranga, V. Environmentally relevant cadmium concentrations affect development and induce apoptosis of Paracentrotus lividus larvae cultured in vitro. Cell Biol. Toxicol. 2008, 24, 603-610.

76. Russo, R.; Bonaventura, R.; Zito, F.; Schröder, H.C.; Müller, I.; Müller, W.E.; Matranga, V. Stress to cadmium monitored by metallothionein gene induction in Paracentrotus lividus embryos. Cell Stress Chaperones 2003, 8, 232-241.

77. Agnello, M.; Filosto, S.; Scudiero, R.; Rinaldi, A.M.; Roccheri, M.C. Cadmium accumulation induces apoptosis in P. lividus embryos. Caryologia 2006, 59, 403-408.

78. Agnello, M.; Roccheri, M.C. Apoptosis: Focus on sea urchin development. Apoptosis 2010, 15, $322-330$.

79. Alhama, J.; Romero-Ruiz, A.; Jebali, J.; López-Barea, J. Total Metallothionein Quantification by Reversed-Phase High-Performance Liquid Chromatography Coupled to Fluorescence Detection after Monobromobimane Derivatization. In Cadmium in the Environment; Parvau, R.G., Ed.; Nova Science Publishers: New York, NY, USA, 2010; pp. 389-405.

80. Samali, A.; Cotter, T.G. Heat shock proteins increase resistance to apoptosis. Exp. Cell Res. 1996, 223, 163-170.

81. Hamada, T.; Tanimoto, A.; Sasaguri, Y. Apoptosis induced by cadmium. Apoptosis 1997, 2, 359-367.

82. Klionsky, D.J.; Abdalla, F.C.; Abeliovich, H.; Abraham, R.T.; Acevedo-Arozena, A.; Adeli, K.; Agholme, L.; Agnello, M.; Agostinis, P.; Aguirre-Ghiso, J.A.; et al. Guidelines for the use and interpretation of assays for monitoring autophagy. Autophagy 2012, 8, 445-544.

83. Lim, S.C.; Hahm, K.S.; Lee, S.H.; Oh, S.H. Autophagy involvement in cadmium resistance through induction of multidrug resistance-associated protein and counterbalance of endoplasmic reticulum stress WI38 lung epithelial fibroblast cells. Toxicology 2010, 276, 18-26.

84. Di Bartolomeo, S.; Nazio, F.; Cecconi, F. The role of autophagy during development in higher eukaryotes. Traffic 2010, 11, 1280-1289.

(C) 2012 by the authors; licensee MDPI, Basel, Switzerland. This article is an open access article distributed under the terms and conditions of the Creative Commons Attribution license (http://creativecommons.org/licenses/by/3.0/). 